\title{
Prediction of deformations in the subsiding soils of Eastern Donbass' undermined areas
}

\author{
Al'bert Prokopov ${ }^{1}$, Anatolii Shuiskii ${ }^{1}$, Evgenii Shcherban' ${ }^{1 *}$, and Vyacheslav Zhur ${ }^{1}$ \\ ${ }^{1}$ Don State Technical University, Gagarin sq., 1, 344000, Rostov-on-Don, Russian Federation
}

\begin{abstract}
Subsiding soils are structurally unstable and are common and Russia (Northern Caucasus, Western Siberia, etc.) as well as worldwide (China, Mongolia, Central Asia, North America, etc.). Construction and operation of buildings and structures on such soils are associated with the nonuniform subsiding of soil due to water saturation, which causes excessive deformations in basements and foundations. The geotechnical and technogenic conditions of Eastern Donbass feature the commonness of subsiding loess soils and undermining of industrial areas prone to waterlogging. The three mentioned factors have a negative impact on ground facilities due to nonuniform vertical and horizontal deformations of the Earth's surface. Despite considerable scientific progress in studying the surficial deformations attributable to various factors, the concurrent effects of undermining, technogenic waterlogging, and manifestation of subsiding properties on the condition of buildings and structures are currently understudied. This paper proposes a method for predicting the deformation of subsiding massifs in the undermined areas of Eastern Donbass. The research team has developed an analytical method for assessing the damage to a typical urban structure simultaneously exposed to soil subsidence and undermining.
\end{abstract}

\section{Introduction}

Subsiding soils are structurally unstable and are common and Russia (Northern Caucasus, Western Siberia, etc.) as well as worldwide (China, Mongolia, Central Asia, North America, etc.). Construction and operation of buildings and structures on such soils are associated with the nonuniform subsiding of soil due to water saturation, which causes excessive deformations in basements and foundations.

Properties of subsiding soils in various regions were studied by leading Russian and international scientists such as Ye.M. Sergeyev, V.I. Osipov [1], Yu.M. Abelev, V.P. Ananyev, V.T. Trofimov [2, 3], etc.

Changes in the properties of basements laid in subsiding loess soils and exposed to watering, as well as design of foundations on subsiding grounds were covered by B.F.

* Corresponding author: au-geen@mail.ru 
Galay, Ya.D. Gilman, B.I. Dalmatov, V.I. Krutov [4], M.V. Prokopova [5], Ye.A. Sorochan, S.M. Cherkasov, A.V. Chmshkyan, etc.

Technogenic waterlogging and flooding of urban industrial areas, as well as the environmental effects of these processes are covered in papers by A.I. Gavrishin [6-9], A.V. Mokhov, A.M. Navitny, A.N. Bogomolov [10], Yu.I. Olyansky [11], A.B. Ponomarev, B.V. Selivanov, G.M. Skibin [12], etc.

The geotechnical and technogenic conditions of Eastern Donbass feature the commonness of subsiding loess soils and undermining of industrial areas prone to waterlogging [4]. The three mentioned factors (Figure 1) have a negative impact on ground facilities due to nonuniform vertical and horizontal deformations of the Earth's surface [1215].

Despite considerable scientific progress in studying the surficial deformations attributable to various factors, the concurrent effects of undermining, technogenic waterlogging, and manifestation of subsiding properties on the condition of buildings and structures are currently understudied. A combination of these negative factors is characteristic of some urban industrial areas in Eastern Donbass (Shakhty, Novoshakhtinsk, Gukovo, Zverevo, Krasny Sulin, Belaya Kalitva, etc.). Condition surveys [13, 14] and analysis of dilapidated housing in the mining towns of Eastern Donbass indicate the relevance of this problem and the need for a method that could predict the geotechnical processes caused by the set of geological and technogenic factors.

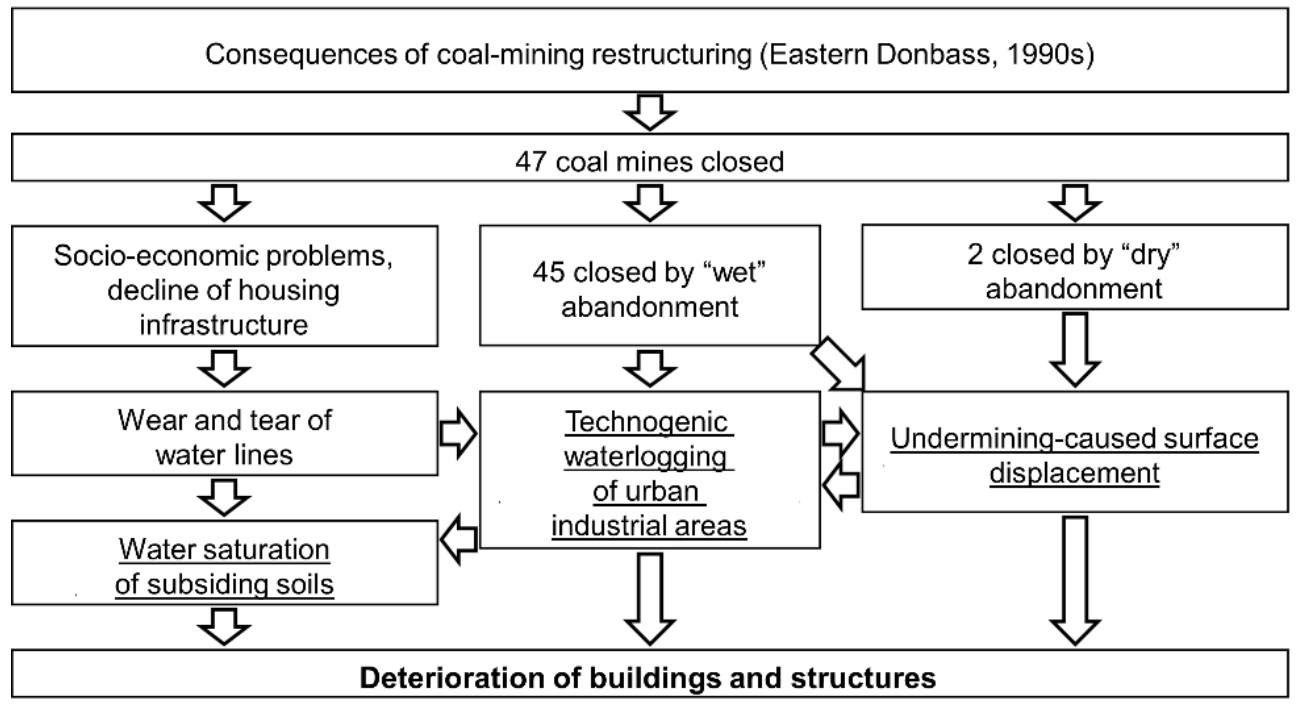

Fig. 1. Disturbances of the normal operation of buildings and structures of Eastern Donbass' urban industrial areas.

\section{Methods}

To evaluate the condition of ground facilities exposed to the negative effects of undermining and subsidence, the authors hereof propose a novel method based on the standards for building design for the considered geotechnical and technogenic conditions. The proposed method for predicting further building operations consists in calculating the integrated score $\Delta \mathrm{l}$, which depends on the building size (in plan view) and height, as well as on the Earth's surface deformations. 
Comparing the terrain subsidence surface cross-sections in undermining and subsidence reveals that within the curvilinear sections of the displacement syncline and subsiding funnel, identical vertical and horizontal displacement zones emerge [6].

Undermining- and subsidence-caused displacements share a common set of parameters: vertical and horizontal displacements, tilts, curvature, and horizontal strain, which are summed to calculate $\Delta \mathrm{l}$.

$$
\Delta l=l \sqrt{m_{\varepsilon}^{2}\left(\sum \varepsilon_{j}^{*}\right)^{2}+m_{k}^{2} H^{2}\left(\sum K_{j}^{*}\right)^{2}}
$$

where: 1 and $\mathrm{H}$ are the building (compartment) length, $\mathrm{mm}$, and the building height from the footing to the cornice top, $\mathrm{m}$;

$\mathrm{m} \varepsilon$ and $\mathrm{mk}$ are work condition factors for a building/structure exposed to horizontal strain $\varepsilon$ and curvature $\mathrm{K}$;

$\sum \varepsilon_{j}^{*}, \sum K_{j}^{*}$ are the calculated horizontal deformation and curvature, $1 / \mathrm{M}$, when simultaneously exposed to undermining and subsidence;

To calculate the parameters $\sum \varepsilon_{j}^{*}, \sum K_{j}^{*}$, find the vertical and horizontal displacements of the funnel cross-section points in a water-saturated ground subsided due to gravity, where I is the tension zone, II is the compression zone, see Figures 2 and 3.

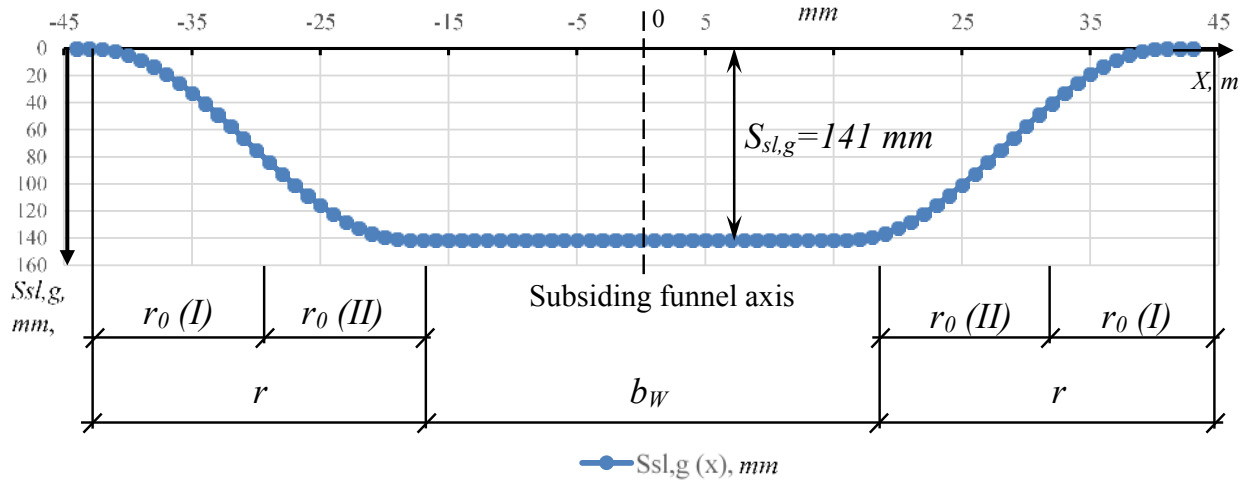

Fig. 2. Vertical displacement of points on the surface of the watered rock mass.

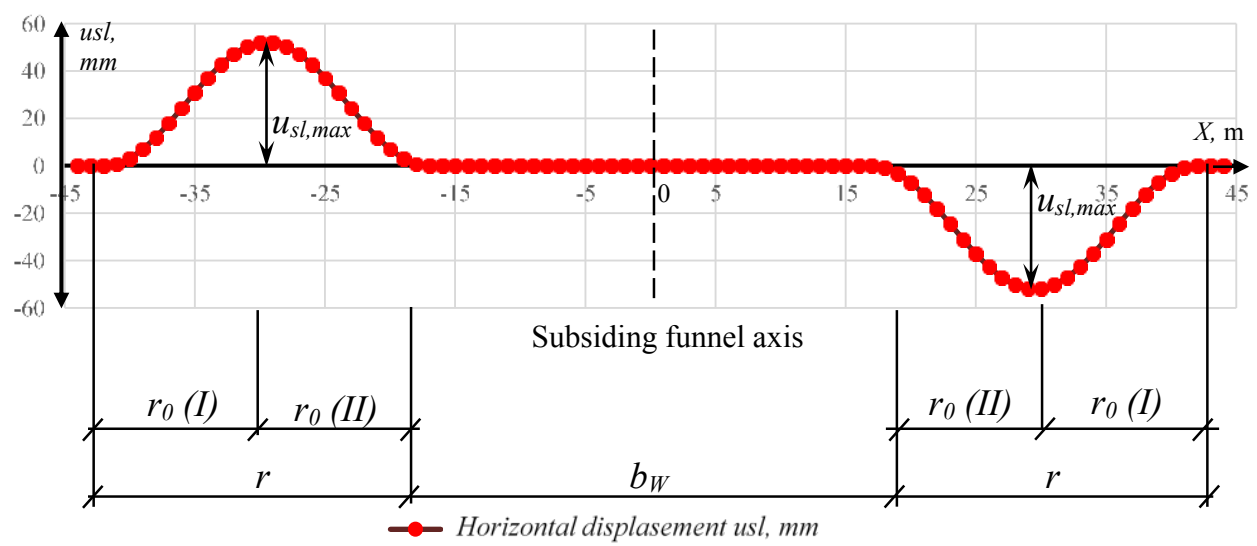

Fig. 3. Horizontal displacement of points on the surface of the watered rock mass. 
The researchers also identified the parameters of surface syncline displacement in a single undermining, see Figures 4, 5.

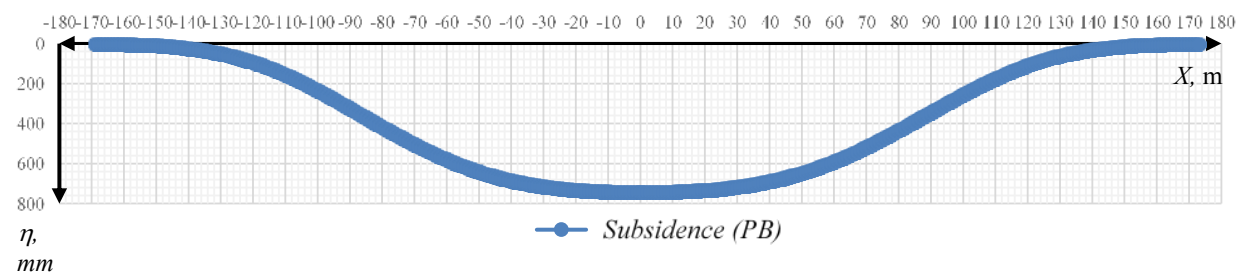

Fig. 4. Subsidence of surface points in undermining.

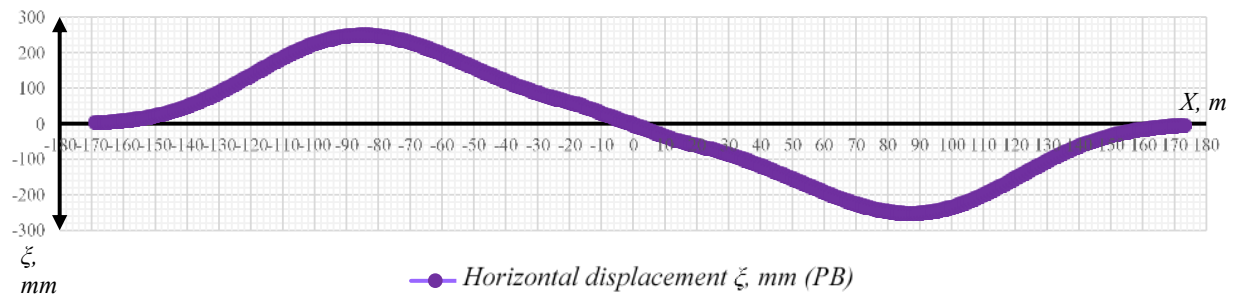

Fig. 5. Horizontal displacement of surface points in undermining.

Vertical and horizontal displacements caused by subsidence and undermining are summed by direction, which produces the total vertical and horizontal displacement plots, see Figures 6 and 7.

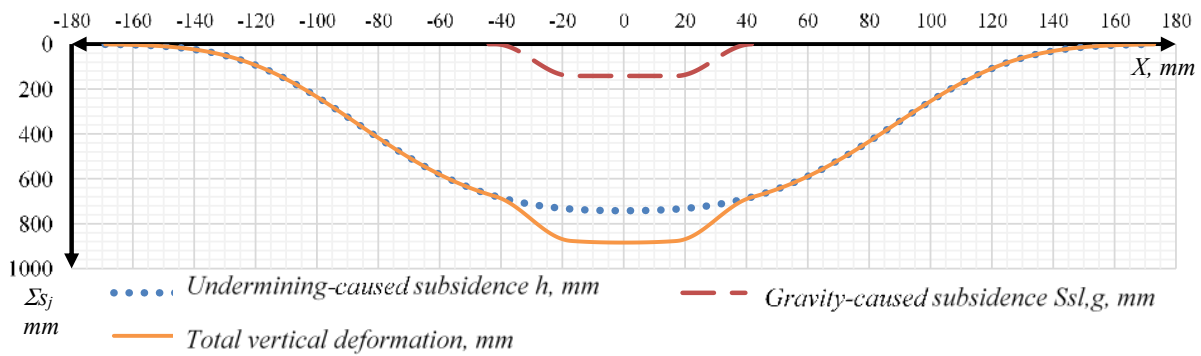

Fig. 6. Total undermining- and subsidence-caused vertical displacements of surface points.

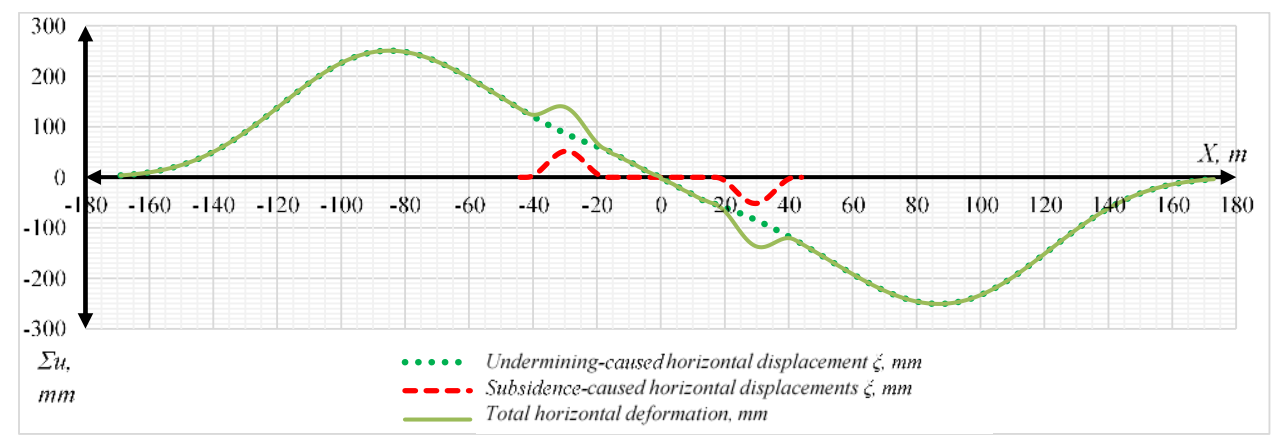

Fig. 7. Total undermining- and subsidence-caused horizontal displacements of surface points . 
Total vertical and horizontal displacements are then used to find the curvature and the horizontal strain in the surface subsidence area.

Curvature is defined as the ratio of difference between inclinations at two points to the distance between the same points:

$$
\sum \varepsilon_{j}^{*}=\frac{\sum i_{j+1}-\sum i_{j-1}}{l_{1}+l_{2}}
$$

where $\sum \mathrm{i}_{\mathrm{j}+1}, \sum \mathrm{i}_{\mathrm{j}-1}$ are the total inclinations at the subsidence curve points to the left and to the right of the point $\mathrm{j}$, respectively.

Horizontal strain is found from the absolute horizontal displacements related to the distance between these points:

$$
\sum \varepsilon_{j}^{*}=\frac{\sum u_{j+1}-\sum u_{j-1}}{l_{1}+l_{2}}
$$

where $\sum \mathrm{u}_{\mathrm{j}+1}, \sum \mathrm{u}_{\mathrm{j}-1}$ are the horizontal displacements at the subsidence curve points to the left and to the right of the point $\mathrm{j}$, respectively.

\section{Results and Discussion}

The proposed method has been used to evaluate the condition of a five-story brick house (Standard 1-447), which is the most common type of housing in the mining towns of Donbass.

Using the geometric parameters of the building and the calculated horizontal deformations and curvature, the research team found the score $\Delta \mathrm{l}$ at the subsiding-surface cross-section points. The permissible $\left[\Delta \mathrm{l}_{\mathrm{p}}\right]_{\max }$ and ultimate $\left[\Delta \mathrm{l}_{\mathrm{u}}\right]_{\max }$ deformations were found as a function of the building design parameters, base soils, wear and tear, configuration, and existing protections. Figure 8 shows the calculation results, where the solid curve shows the distribution of the calculated $\Delta \mathrm{l}$, the dash-dotted horizontal line shows the permissible deformation, while the dashed horizontal line shows the ultimate deformation. The ultimate deformation can be used to evaluate effects by the first group of limit states; permissible deformation is applicable to the second group.

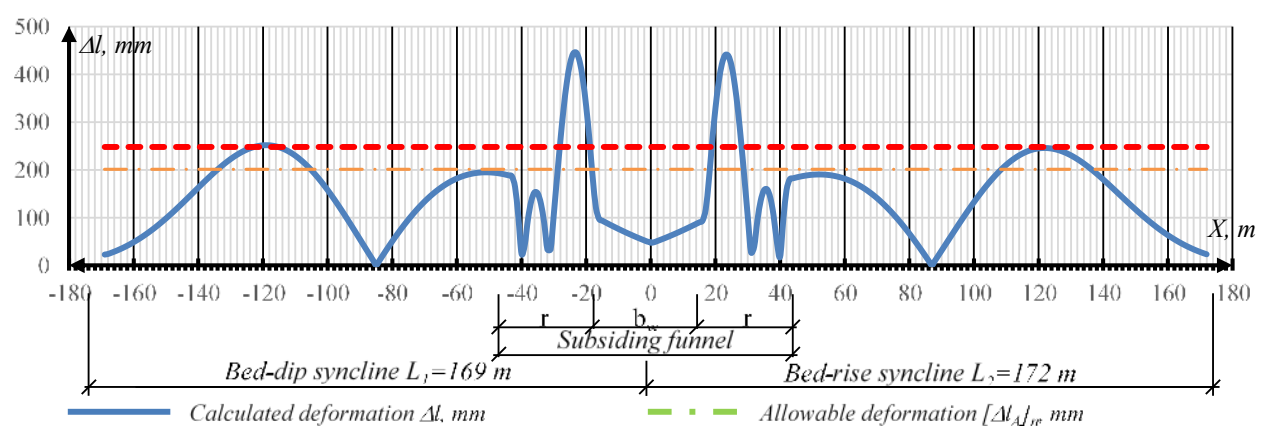

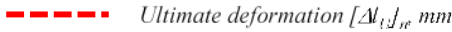

Fig. 8. Calculated deformation $\Delta \mathrm{I}, \mathrm{mm}$.

The condition of an undermining- and subsidence-exposed waterlogged structure is determined by the maximum value of the integrated score $\Delta \mathrm{l}$ within the building outline as compared to the permissible deformation $\left[\Delta \mathrm{l}_{\mathrm{p}}\right]_{\max }$ and ultimate deformation $\left[\Delta \mathrm{l}_{\mathrm{u}}\right]_{\max }$. The following evaluations are possible: 
1) If $\Delta \mathrm{l}<\left[\Delta \mathrm{l}_{\mathrm{p}}\right]_{\max }$, the building can be operated further without major restrictions or overhauls/reconstructions. Redecoration may be desirable though.

2) If $\left[\Delta \mathrm{l}_{\mathrm{p}}\right]_{\max } \leq \Delta \mathrm{l}<\left[\Delta \mathrm{l}_{\mathrm{u}}\right]_{\max }$, further use of the building might be difficult or have to cease temporarily, as action must be taken to eliminate the effects of nonuniform deformations in underground and above-ground structures, to reinforce the building, and to begin geotechnical monitoring.

3) If $\Delta \mathrm{l} \geq\left[\Delta \mathrm{l}_{\mathrm{u}}\right]_{\max }$, the building must be abandoned and can be declared dilapidated after examined and tested for its bearing capacity.

Consider a building located in an area of nonuniform undermining- and subsidencecaused deformations, see Figure 9.

Calculating the deformation score $\Delta \mathrm{l}$ for comparison against the permissible value $\left[\Delta \mathrm{l}_{\mathrm{p}}\right]_{\mathrm{n}}$ and ultimate value $\left[\Delta l_{\mathrm{u}}\right]_{\mathrm{n}}$ can help evaluate the effects of geotechnical processes on the building condition. This problem has been solved for each point of the subsidence surface. Analysis of estimates shows that the most critical damage to the building according to the condition $\Delta \mathrm{l} \geq\left[\Delta \mathrm{l}_{\mathrm{u}}\right]_{\max }$ is noted where $\mathrm{X}_{\mathrm{j}} \in[-122 ;-116]$, as well as within the limits of the areas of compression $r_{0 I I}$ in the curvilinear section of the subsiding funnel $r$, where $X_{j} \in[-$ $28 ;-19]$ and $X_{j} \in[19 ; 28]$. Then the length of the intervals projected to have maximum damage does not exceed 10 meters. Since the building under consideration is $71.2 \mathrm{~m}$ long, it can belong to any category: further operation allowed, further operation allowed with restrictions, further operation not allowed due to dilapidation.

Consider six variants of building positioning within an area of nonuniform undermining- and subsidence-caused deformations (Figure 9).

For each position, find minimum, maximum, and mean value of $\Delta \mathrm{l}$ within the building outline. See Table 1 for results

Table 1. Deformation score comparison for each building position.

\begin{tabular}{|c|c|c|c|c|}
\hline \multirow{2}{*}{$\begin{array}{c}\text { Building } \\
\text { position }\end{array}$} & \multirow{2}{*}{$\begin{array}{c}\text { Interval within the } \\
\text { deformation area }\end{array}$} & \multicolumn{3}{|c|}{ Deformation score $\Delta$ I, mm } \\
\cline { 3 - 5 } & {$[-160 ;-88]$} & 164 & Minimum & Maximum \\
\hline 1 & {$[-130 ;-58]$} & 155 & 33 & 252 \\
\hline 2 & {$[-101 ;-29]$} & 122 & 1 & 252 \\
\hline 3 & {$[-91 ;-19]$} & 156 & 1 & 195 \\
\hline 4 & {$[-72 ; 0]$} & 163 & 24 & 445 \\
\hline 5 & {$[-36 ; 36]$} & 163 & 28 & 445 \\
\hline 6 & & & & 445 \\
\hline
\end{tabular}

As can be seen from Table 1 , the mean calculated values of $\Delta \mathrm{l}$ do not exceed the permissible value $[\Delta \mathrm{l} p] \mathrm{max}$ in any position, meaning that the building operation can be continued, which is doubtful. Therefore, quantitative prediction of the effects of geotechnically caused displacements shall use the maximum calculated value of $\Delta \mathrm{l}$ for the building.

Analytic prediction of the building serviceability has to be confirmed by field observations or by simulation in special software for structural computing.

For the worst-case scenario (Position \#5 in Figure 9), the maximum, minimum, and mean value of $\Delta 1$ within the building outline equal 445,24 , and $163 \mathrm{~mm}$, respectively. In some sections, the deformations $\Delta \mathrm{l}$ exceed permissible and ultimate values, see Figure 8; this means that further operation is not permissible as the building is dilapidated. 

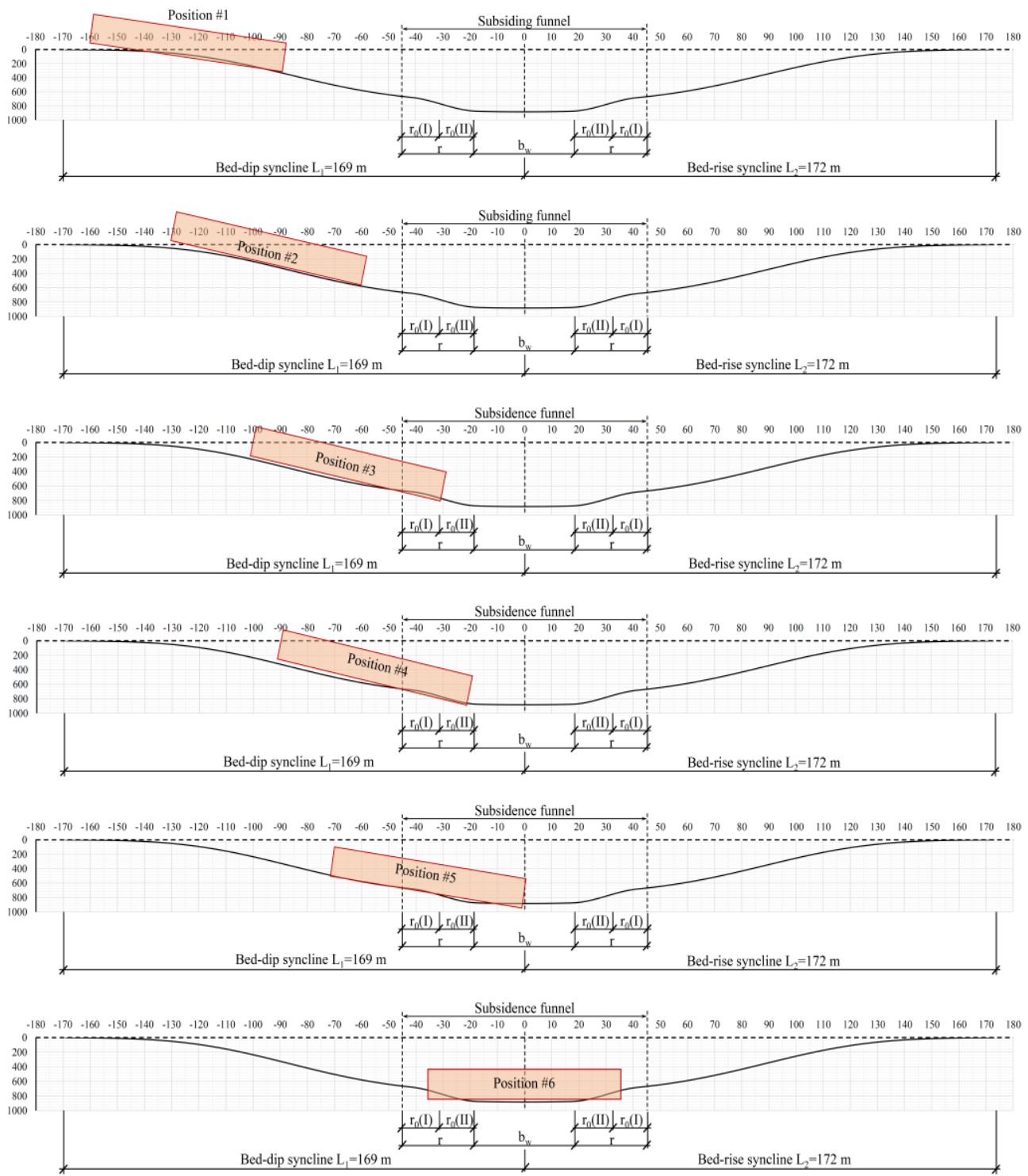

Fig. 9. Building positions within the analyzed displacement and subsidence area.

\section{Conclusions}

The research has produced the following key results:

1. The full set of parameters (vertical subsidence, horizontal displacement, inclination, curvature, and horizontal strain) has been determined for calculating the deformation score affected by both undermining and subsidence. Despite the fact that both methods are regulated by the same SP 21.13330, calculations use absolutely different inputs, which means none of the displacement parametrization steps can be merged. However, the rule of signs for the two groups of deformation parameters in undermining and subsidence is universal. 
2. Since deformations were calculated as a function of subsidence and undermining at points of the deforming surface with a pitch of $1 \mathrm{~m}$, no constraints were identified for finding the total deformation in relation to vertical and horizontal axes. Total and vertical point displacements were plotted.

3. Summation of displacements in two mutually perpendicular directions produced the deformation parameters (inclinations, curvature, and horizontal strain). The research team verified two methods of finding these values; one implied summing the parameters found independently for undermining and subsidence; the other one used total displacement calculations. The rule of signs was taken into account; according to this rule, vertical displacement implies subsidence and drawdown; in horizontal displacements, + stands for tension, - stands for compression. It was found that the difference in the results obtained by these two methods did not exceed $1 \%$ on average, or $30 \%$ point-specifically. It was decided to further use only the new method that involved total vertical and horizontal displacements.

4. One of the key outcomes of this research is calculating the actual deformation $\Delta \mathrm{l}$ as caused by simultaneous exposure to undermining and subsidence. The results were used to analyze the damage sustained by a structure; the analysis was based on long-term observations of surficial displacements in undermined areas. The observations identified the nature of damage to the basic structural elements (walls, partitions, floors, and piers) as a function of the score $\Delta \mathrm{l}$, height in floors, and building deterioration.

5. Further serviceability of the building was predicted by comparing the maximum calculated value of $\Delta \mathrm{l}$ against the permissible value $\left[\Delta \mathrm{l}_{\mathrm{p}}\right]_{\mathrm{n}}$ and the ultimate value $\left[\Delta \mathrm{l}_{\mathrm{u}}\right]_{\mathrm{n}}$ for a point that belonged to the interval, the borders of which matched the external outline of the analyzed building/structure.

6. The most critical damage to the building according to the condition $\Delta \mathrm{l} \geq\left[\Delta \mathrm{l}_{\mathrm{u}}\right]_{\max }$ was noted in the limits of the areas of compression $\mathrm{r}_{0 \mathrm{II}}$ in the curvilinear section of the subsiding funnel $r$, where $X_{j} \in[-28 ;-19]$ и $X_{j} \in[28 ; 19]$.

7. For any points, the calculated residual building life $t_{0}>0$, which means that immediate demolition or implementation of protections per PB 07-269-98 would not be necessary.

8. Despite no immediate demolition being necessary per the residual life $t_{0}$, further use of the building in the compression areas $r_{0 I I}$ of the subsiding funnel remains questionable.

Analytic prediction of the building serviceability has to be confirmed by field observations or by simulation in special software for structural computing.

Thus, this paper proposes a method for predicting the strain of subsiding massifs in undermined areas. An analytical method has been developed for evaluating the condition of buildings and structures; the method is based on finding the total vertical and horizontal displacements caused by the combined effects of undermining and soil subsidence.

The reported study was funded by FSBEI HE DSTU under the University Grants for Scopus and Web of Science publications.

\section{References}

1. V. Osipov, V. Burova, E. Karfidova, Soil Mechanics and Foundation Engineering 53, 6 (2017). DOI: 10.1007/s11204-017-9422-z.

2. V. Trofimov, Moscow University Geology Bulletin 71(6), 457-461 (2016). DOI: 10.3103/S0145875216060119.

3. V. Trofimov, S. Balykova, Doklady Earth Sciences 413(2), 164-166 (2007). DOI: 10.1134/S1028334X07020031. 
4. V. Krutov, Soil Mechanics and Foundation Engineering 52(1) (2015). DOI 10.1007/s11204-015-9304-1.

5. A. Prokopov, M, Prokopova, Ya. Rubtsova, MATEC Web of Conferences 106, 02001 (2017). DOI: https://doi.org/10.1051/matecconf/201710602001.

6. A. Gavrishin, Water Resources 45(5), 785-794 (2018). DOI: 10.1134/S0097807818050081.

7. A. Gavrishin, Gornyi Zhurnal 1, 92-96 (2018). DOI: 10.17580/gzh.2018.01.17.

8. A. Gavrishin, Doklady Earth Sciences 481(1), 916-917 (2018). DOI: https://doi.org/10.1134/S1028334X18070127.

9. M. Molev, V. Armeiskov, M. Golodov, Mining Informational and Analytical Bulletin 3, 63-73 (2019). DOI: 10.25018/0236-1493-2019-03-0-63-73.

10. A. Bogomolov, Y. Olyanskii, E. Shchekochikhina, Soil Mechanics and Foundation Engineering 55(2) (2018). DOI: 10.1007/s11204-018-9509-1.

11. Yu. Olyansky, E. Shekochihina, S. Kalinovsky, IOP Conference Series: Materials Science and Engineering 463 (2018). DOI:10.1088/1757-899x/463/4/042058.

12. M. Shutova, G. Skibin, S. Evtushenko, IOP Conference Series: Materials Science and Engineering 262 (2017). DOI: 10.1088/1757-899X/262/1/012061.

13. P. Dolzhikov, A. Prokopov, V. Akopyan Advances in Intelligent Systems and Computing 692 (Springer, Cham, 2017). DOI: https://doi.org/10.1007/978-3-31970987-1_69.

14. A. Prokopov, V. Zhur, A. Medvedev, MATEC Web of Conferences 196, 03009 (2018). DOI: https://doi.org/10.1051/matecconf/201819603009.

15. G. Chen, T. Li, Y. He, L. Wei, Z. Zhou, Tumu jianzhu yu huanjing gongcheng 35(1), 52-56 (2013). DOI: 10.3969/j.issn.1674-4764.2013.01.009. 